\title{
Una forma moderna de sociabilidad: Inicio de la Masonería en Chile (1862) ${ }^{* *}$
}

\author{
A modern form of sociability: The beginning \\ of the Masonry in Chile (1862) \\ Uma forma moderna de sociabilidade: Início \\ da Maçonaria no Chile (1862)
}

\footnotetext{
* Profesor de Historia y Geografía por la Universidad Adventista de Chile, Magíster en Historia de Occidente por la Universidad del Bío-Bío, Doctorando en Historia Universidad de los Andes. Actualmente Director del Centro Histórico y Académico del Departamento de Historia de la Universidad Adventista de Chile, donde también realiza actividades de investigación sobre historia social, de la educación y sociabilidad durante los siglos XIX y XX en Chile. Universidad Adventista de Chile/Universidad los Andes (Chile).

** El presente artículo forma parte de la Tesis de Magíster «La Masonería en Chile y su presencia en la Educación 1860-1920», Universidad del Bío-Bío, Chile. Artículo de investigación recibido el 05.04.2017 y aceptado el 27.10.2017.
} 


\section{Cómo citar}

PARADA UlloA, M. (2018). Una forma moderna de sociabilidad: Inicio de la Masonería en Chile (1862). Revista CS, (24), 119-146.

DOI: http://dx.doi.org/10.18046/recs.i24.2404 
Resumen

Abstract

Resumo

El presente estudio es un análisis heurístico e interpretativo cuyo propósito es analizar los antecedentes fundacionales de la masonería en Chile durante la segunda mitad del siglo XIX. Para ello, se identifican las vías de ingreso de los extranjeros al territorio latinoamericano y nacional: los puertos del Pacífico que permitieron la fundación de logias. En el caso de Chile, la masonería ingresó a través de los puertos de Valparaíso y Talcahuano: la movilidad de comerciantes, artesanos y profesionales de origen británico, francés y norteamericano, permitió la llegada de la Orden a las ciudades de Concepción y Copiapó. La institucionalización de la masonería en Chile se dio con la fundación de la Gran Logia de Chile, en 1862, que favoreció la consolidación de la Orden en el país, la fundación de logias en distintas ciudades y la iniciación de chilenos durante las siguientes décadas.

\section{PALABRAS CLAVE:}

Masonería; Modernidad; Sociabilidad; Valparaíso; Chile.

The present study is a heuristic and interpretative analysis of, the foundational history of masonry in Chile during the second half of the nineteenth century. For this purpose, I identified the entrance routes of foreigners into Latin American and Chile. Masonry entered into Chile through the Pacific ports of Valparaíso and Talcahuano. Thanks to the mobility of merchants, artisans and professionals of British, French and North American descent, the masonic Order was established in the cities of Concepción and Copiapó. The institutionalization of masonry in Chile started with the foundation of the Gran Logia de Chile (The Great Lodge of Chile) in 1862, which favored the consolidation of the Order inside the country. In the next decades, masonry expands to other cities with the foundation of lodges involving Chileans as well.

\section{KEYWORDS:}

Masonry; Modernity; Sociability; Valparaíso; Chile. 
O presente estudo é uma análise heurística e interpretativa e cujo propósito é analizar os antecedentes funcionais da maçonaria no Chile durante a segunda metade do século XIX. Para isso, identificam-se as vias de ingresso dos estrangeiros ao território latino americano e nacional os portos do Pacífico que permitiram a fundação das logias. No caso do Chile, a maçonaria ingressou através dos portos de Valparaiso e Talcahuano: a mobilidade de comerciantes, artesãos e profissionais de origem britânica, francês e norte americano, o que permitiu a chegadas da ordem à cidades de Concepción e Copiapó. A institucionalização da maçonaria no Chile se deu com a fundação da Grande Logia do Chile, em 1862, que favoreceu a consolidação da ordem no país, a fundação de logias em diferentes cidades e a iniciação dos chilenos durante as seguintes décadas.

\section{PALAVRAS CHAVES:}

Maçonaria; Modernidade; Sociabilidade; Valparaiso; Chile. 


\section{Introducción}

El tránsito a la modernidad en Chile durante el siglo XIX debe ser observado en los cambios socioculturales que condicionaron el tránsito de una sociedad tradicional a otra que intenta insertarse en el desarrollo y el progreso modernos. La participación de extranjeros en actividades sociales, comerciales y en asociaciones fue reflejo de progreso y civilidad, como formas de sociabilidad.

François Chevalier (1999) comprende que los cambios efectuados en Hispanoamérica durante la primera mitad del siglo XIX favorecieron la llegada de las ideas liberales. Al respecto, Maurice Agulhon (1990) señala que el establecimiento de asociaciones permitirá un cambio sociocultural: la aparición de la sociabilidad está relacionada con los lazos interpersonales de un grupo humano. Esto representa una dimensión de la realidad histórico-social, pues la sociabilidad debe ser entendida como la manera en que los hombres viven sus relaciones interpersonales en el lugar que los rodea. En este sentido, destaca las nuevas formas de sociabilidad como los clubes, las tertulias, las sociedades filantrópicas y las logias masónicas, que son manifestación de la modernidad.

Estas asociaciones serán un espacio de encuentro y de opinión entre sus miembros. En el caso de las logias masónicas, estas son un lugar de encuentro y de trabajo masónico donde «los individuos no se distinguen entre sí por su condición jurídica y donde sólo el mérito puede justificar la obtención de grados y dignidades» (Chartier, 2003: 180-183).

Las logias masónicas impulsarán nuevas formas de sociabilidad al romper las características del antiguo régimen. Deben ser entendidas desde una perspectiva pluriformal, pues tienen un espacio de marco normativo y una funcionalidad múltiple: educativa, espiritual, cultural o política; pero también son un lugar de simbolismo ritual. Dentro de ellas se practica la fraternidad entre los miembros, se crean lazos y amistades, y se desarrollan actividades a través de tenidas y ágapes (Martín, 2003: 524-554), produciendo una bisagra cultural entre lo privado y público que permite el accionar de sus miembros en actividades de distinta índole en el mundo profano.

Dentro de este contexto, la masonería impulsó el «libre desenvolvimiento de la razón como el don más preciado que se le ha dado al hombre» (Guerra, 1993: 13). Esto quiere decir la libertad de pensamiento y el desarrollo de una sociedad de tipo igualitario bajo el prisma democrático. Importa observar que el sustento filosófico de la masonería ha sido desarrollado por principios y códigos de conducta moral; pero, si se la considera cuidadosamente como forma asociativa, pudo desarrollar una estrategia política, ideológica con valores-culturales, y junto con ella nuevas elites políticas gracias al ascenso de los regímenes liberales. Esto significó que las 
logias formaron círculos de opinión política durante la segunda mitad del siglo XIX en Chile, a través de agrupaciones civiles, ingresando en las esferas del poder público, y pronunciándose a través de sus miembros sobre diversos temas educativos, sociales y económicos de la realidad chilena.

En consecuencia, el presente artículo analizará el establecimiento de la masonería en territorio nacional y los factores que llevaron a su institucionalización durante la segunda mitad del siglo XIX. Por lo tanto, en las siguientes páginas se pretende responder la interrogante ya planteada.

\section{Llegada de la masonería a Hispanoamérica}

La llegada y desarrollo de la Francmasonería en América fue un claro reflejo y trasposición de la situación de la masonería en Europa durante el siglo XVIII y a comienzos del XIX (Ferrer, 2009: 4). Dicha institución estaba formada principalmente por hombres de la política y del ejércitoํㅜ (Cerza, 1977: como se citó en Ferrer, 2009), quienes lograron una «rápida implantación con la creación de Grandes Logias en las trece colonias entre 1778 y 1794» (Ferrer, 2009: 4).

José Ferrer ha señalado que la masonería británica ha estado presente en los Estados Unidos de Norteamérica desde los tiempos de la independencia, pues en todos los regimientos británicos había una logia masónica incorporada, «asimismo logias militares agregadas a algunos regimientos del ejército colonial». Esta forma de sociabilidad desarrollada en Norteamérica será un «puente de penetración en las colonias españolas, especialmente de las Antillas y Centro-América» (Ferrer, 2009).

Otro foco de penetración fue la isla de Jamaica, en donde hacia 1770 existían cinco logias inglesas y una escocesa. Esto favoreció la fundación en Curazao de otra logia llamada «Antillas holandesas, con patente emitida por la Gran Logia Provincial de Jamaica en 1774» (Ferrer, 2009: 5). Como luego la masonería jamaicana ya no dependerá de la masonería inglesa, sino de la jurisdicción del Gran Oriente de los Países Bajos, habrá una apertura de La Gran Logia Provincial de Jamaica para constituir diferentes logias fuera de la isla. En Cartagena (Nueva Granada), se estableció la logia Britannia $\mathrm{N}^{\circ} 1$, y en 1808 se fundó la logia Las Tres Virtudes Teologales. En Bogotá se creó en 1820 la logia Libertad de Colombia, cuyo nombre cambiará por

1. De las 56 firmas que figuran al pie de la Declaración de Independencia, nueve corresponden a masones con toda seguridad, y hay dudas respecto a otros 26. De las 39 firmas que hay en la Constitución de Estados Unidos, hay pruebas de que 13 corresponden a masones, existiendo posibilidades de otros siete. De los 74 generales que tuvo a sus órdenes George Washington, 33 indudablemente pertenecían a la masonería y quizá otros 15 más. 
Fraternidad Bogotana. En 1821 y 1822 fueron fundadas en Cartagena y Medellín las logias Beneficencia y La Concordia (Ferrer, 2009). El desarrollo de la sociabilidad se dio gracias a la presencia de masones franceses y escoceses que colaboraron en la instalación de logias en Centroamérica entre 1813 y 1846 (Renault, 2009; Valdés-Valle, 2009), lo que favoreció la iniciación de personas de distintas nacionalidades y promovió su llegada a otras zonas del continente.

Por otra parte, la España del siglo XVIII tendrá una relación bien complicada con la masonería, pues prohibirá su ingreso y condenará a sus miembros (Bastián, 1999: 125). La presencia de la masonería se realizará a través del ejército: hay evidencia de que en las ocupaciones e invasiones inglesas a Gibraltar y la isla Menorca, fueron establecidas rápidamente logias militares. En 1762 la masonería llegó a Cuba cuando Gran Bretaña se apoderó de la isla. Durante la ocupación funcionó la logia militar $\mathrm{N}^{\circ} 218$, constituida por el regimiento número 48 de tropas irlandesas, que permaneció en Cuba hasta el 6 de junio de 1763. Se puede afirmar que la masonería en el Caribe se introduce por tres vías: inglesa, norteamericana y francesa (Ferrer, 2009).

La masonería se establece en Hispanoamérica a fines del siglo XVIII y comienzos del XIX. En Argentina se funda la logia Independencia (Martínez, 1965: como se citó en Ferrer, 2009) con carta Constitutiva del Gran Oriente de Francia; y en «1799 la logia San Juan de Jerusalén que funcionará hasta 1806» (Ferrer, 2009). En 1818 el inglés James Hamilton fundó la logia La Concordia Venezolana, bajo la autoridad de la Gran Logia Provincial de Kingston (Jamaica); y en 1821 en Caracas aparece el taller La Unión, dependiente de la Gran Logia de Pennsylvania. Así como otras logias creadas entre 1821 y 1841.

A comienzos del siglo XIX, especialmente después de las independencias y de la transformación de las colonias en repúblicas soberanas, la masonería se introduce y se organiza en las incipientes repúblicas. En la mayoría de estas nuevas naciones -Perú, México, Uruguay, Costa Rica, Paraguay, Panamá, Bolivia-fue posterior a la independencia (Ferrer, 2009:11-12). En Perú, «antes de 1819 fue instalada en Lima la Logia Paz y Perfecta Unión y en 1822 la logia Virtud y Unión» (Sepúlveda, 1994: 18).

Además hay que considerar que la transición entre logias masónicas y organismos políticos de lucha por la emancipación de los territorios americanos, se realizó a través de distintas instancias por ejemplo:

[...] la sociedad secreta [bajo el nombre Arcano Sublime de la Filantropía] creada por Nariño en el Virreinato de Nueva Granada en 1792 y las Logias de Caballeros Racionales o Lautarinos en Buenos Aires, Mendoza, Santiago, Lima [...] organizadas por San Martín, O’Higgins y otros patriotas y masones (Sepúlveda, 1994: 18). 
La participación de Francisco de Miranda iniciada en Londres (1806-1816) tuvo como objeto buscar la independencia de Hispanoamérica a través de la organización de la Gran Reunión Americana, con filiales en París y Madrid bajo el nombre de Juntas de las Ciudades y Provincias de América Meridional. Además de otra filial establecida en Cádiz con el nombre de Caballeros Racionales² (Sepúlveda, 1994:19). En 1812 se funda en Buenos Aires la logia Caballeros Racionales, cuyo propósito fue la independencia de las provincias unidas y de Hispanoamérica.

\section{Ingreso de la Masonería a Chile}

A comienzos del siglo XVIII los borbones llegaron al poder y se estableció una política de control social en Hispanoamérica, como diría Lynch (1985): fue desarrollada una segunda conquista, desde la perspectiva burocrática. Aunque prevalecía el control establecido por los peninsulares en aspectos económicos, políticos y culturales, no impidió que las colonias fueran adquiriendo un nacionalismo incipiente.

Para Santiago del Solar, el aislamiento geográfico de Chile y «su relación indirecta e informal con el comercio atlántico y su modesto intercambio cultural con Europa, constituía un enclave tradicional de la cultura colonial española donde la ya limitada ilustración hispánica llegaba aún más tenue. Esta situación fue mitigada con la aplicación de reformas borbónicas que permitieron comerciar con otras potencias marítimas, lo cual ayudó al ingreso continuo pero controlado de la modernidad (Del Solar, 2012: 18).

Sin embargo, lo que lleva a España a perder el control de sus colonias durante la segunda mitad del siglo XVIII, fue que Gran Bretaña empezó a comerciar con las colonias a través del contrabando; lo que favoreció el establecimiento de nuevas formas de comercio y de sociabilidad. La Cédula real de 1778 permitió el libre comercio entre Buenos Aires, Chile y Perú, siendo este un canal de comunicación formal entre los dos virreinatos.

En 1796 los británicos bloquearon el puerto de Cádiz, mermando el poder peninsular para controlar sus colonias, y que los hispanoamericanos pudieron comerciar con plena libertad, es decir, apertura de los puertos y comercio directo con los extranjeros: comerciantes ingleses, franceses y en menor medida norteamericanos (Halperin, 1990).

2. Los principales patriotas que participaron en los talleres mirandistas podemos señalar: Bernardo O'Higgins, José Miguel Carrera, Juan Martínez de Rozas, José Gregorio Argomedo, Juan Antonio Rojas, los argentinos José de San Martín, José María Zapiola, Carlos María Alvear, Mariano Moreno; el boliviano Bernardo Monteagudo; el fraile dominicano Servando Teresa de Mier, en México, entre otros. (Sepúlveda, 1994). 
Siguiendo a del Solar, otra vía de comunicación y transferencia fueron los viajes de los criollos a Europa:

[...] quienes por motivos académicos, comerciales o militares entraban en contacto con las ideas y formas de sociabilidad europeas. Destacan [...] Bernardo O'Higgins y José Miguel Carrera. El primero estudio y fue discípulo de Francisco Miranda. En el segundo caso sirvió en el ejército Real (Del Solar, 2010: 5).

En cuanto a las fuentes intelectuales, las reformas borbónicas establecieron un control del pensamiento y las ideas en Hispanoamérica. Surgió cierta molestia entre algunos criollos que percibían que la censura, la ausencia de imprenta y la escasez de libros originaban un retraso cultural y les impedía lograr mayor desarrollo de las colonias $^{3}$ (Lynch, 1985). Sin embargo, François-Xavier Guerra (1993), ha considerado el rol modernizador de la prensa, pues la aparición del periódico permitió establecer espacios de sociabilidad dentro de la ciudadanía en Hispanoamérica, siendo una instancia de expresión discursiva para educar, civilizar y establecer un proyecto valórico-cultural centrado en los derechos del hombre, la libertad y la soberanía, orientada a educar al pueblo y deslegitimar el antiguo régimen (Parada, 2015:124).

Algunos criollos cultos eran «algo más que reformadores; eran revolucionarios» (Lynch, 1985), entre ellos: Francisco de Miranda, Pedro Fermín de Vargas, Antonio Nariño y Simón Bolivar, buscadores de la libertad y felicidad humana (Del Solar, 2012: 18-19). En el caso de nuestro país, está el caso de «José Antonio de Rojas, quien introdujo en Chile un importante cargamento de libros franceses» (Jocelyn-Holt, 2001: 41).

En 1808, el ejército francés invadió España y el Rey Fernando VII fue tomado prisionero. Esto permitió el ingreso de la modernidad, las ideas ilustradas y el posicionamiento de la masonería, que colaboraría con los procesos independentistas en Hispanoamérica. Durante este período la masonería tenía marcado carácter político, y sus miembros fueron criollos de formación militar que colaboraron en proyectos independentistas en sus lugares de origen (Del Solar, 2004: 5-6; Chevalier, 1999).

La llegada de la masonería a Hispanoamérica se hizo a través de militares y comerciantes extranjeros que llegaron a los principales puertos de las costas del Pacífico, ejemplo de ello fue la llegada de buques a las costas del Río de la Plata:

3. Lynch no comparte este punto, ya que las ideas de los filósofos ilustrados eran «conocidas por los americanos aunque no fueran aceptadas indiscriminadamente. La literatura de la ilustración circulaba en Hispanoamérica con relativa libertad». Ejemplo de ello, México tenía un público de Newton, Locke, Voltaire, entre otros. Los lectores eran de sectores altos, principalmente. El nuevo movimiento intelectual «no era un asunto que dividiera a los criollos de los españoles, no era un ingrediente esencial de la independencia». 
«pues cada uno de ellos eran logias flotantes, con la misión de levantar el espíritu popular y fundar logias donde quiera que sus anclas dieran fondo» (Pinto, 1966: 45).

En los puertos de Valparaíso y Concepción, esta última: «centro de gran atracción comercial y militar por su proximidad a Talcahuano, importante puerto chileno para las naves procedentes del viejo mundo» (Pinto, 1966: 51-52) adonde llegaron comerciantes ingleses y norteamericanos, muchos de ellos masones, permitiendo el desarrollo de la sociabilidad, la cultura y la integración económica de Chile con el mundo.

En síntesis, el comercio con ingleses y norteamericanos, luego de la desintegración del monopolio español durante las guerras napoleónicas, permitió que las zonas del Río de la Plata y las costas del Pacífico, fueran un canal no solo «para mercancías y servicios, sino para libros e ideas» (Lynch, 1985). Y también la vía de entrada de la masonería en Chile.

El rey Fernando VI prohibió la masonería en sus dominios mediante decreto en Aranjuez el 2 de julio de 1751:

He resuelto atajar tan graves inconvenientes con toda mi autoridad; y en su consecuencia prohíbo en todos mis Reinos las Congregaciones de los Franc-Masones, debajo de la pena de mi Real indignación, y de las demás que tuviese por conveniente imponer a los que incurrieren en esta culpa: Y mando al Consejo, que haga publicar esta prohibición por Edicto en estos mis Reinos, encargando en su observancia, el celo de los Intendentes, Corregidores y Justicias, aseguren a los contraventores, dándome cuenta, de los que fueren, por medio del mismo Consejo, para que las penas que merezca el escarmiento: En inteligencia, de que he prevenido a los Capitanes Generales, a los Gobernadores de Plazas, Jefes Militares e Intendentes de mis Ejércitos, y Armada Naval, hagan notoria, y celen la citada prohibición, imponiendo a cualquier Oficial, o Individuo de su jurisdicción, mezclado o que se mezclare en esta Congregación, la pena de privarle y arrojarle de su empleo con ignominia. Tendráse [sic] entendido en el Consejo, y dispondrá su cumplimiento en la parte que le toca (Ferrer, 1986: 432, Romo: 2009: 30).

En 1756 se encuentra uno de los primeros antecedentes sobre la presencia de la masonería en Hispanoamérica y en Chile. El gobernador teniente coronel Ambrosio Sáez de Bustamante del presidio de Valdivia, fue acusado de ser francmasón (Ferrer, 1973: como se citó en Del Solar, 2010: 4; Romo, 2009: 29). A pesar de la gravedad de la acusación, Sáez continúo desempeñando el cargo y terminó sus días en España como gobernador de Mérida en Cataluña (Romo, 2009). Lo más probable es que fue iniciado en las campañas militares en las que participó en Italia, pero salió absuelto del juicio de residencia. 
En 1773 fue denunciado ante la inquisición de Lima el cirujano francés M. Lagrange, que quiso practicar en Lima la fraternidad masónica que había traído de Francia y tuvo la «debilidad de confiar su secreto a una mulata limeña quien va a contarlo a la Santa inquisición, con lo que empiezan las desgracias del pobre hombre» (Medina, 1887; Picón, 1929: 234).

La Ilustración española no favoreció la llegada de la masonería, pero difundió la noticia de su existencia alertando a las autoridades sobre su peligro y no fue hasta la caída de Fernando VII en 1808, que la masonería logró establecerse y siendo una posibilidad para elites del mundo hispano, más que las ideas de las luces fue la revolución que favoreció el surgimiento de hermandades secretas (Del Solar, 2010: 21).

La crisis ideológica provocada primero por la independencia de Estados Unidos y después por la revolución francesa con su corolario de luchas y renuncias en el suelo español, trajo como consecuencia la expansión de doctrinas y tácticas políticas que habrían de elevar a la categoría de ideales los elementos de esa trilogía inseparable de libertad, igualdad y fraternidad. En ella bebieron no solo los europeos-algunos de los cuales vinieron a América-, sino también los americanos de paso por el occidente europeo (Peña, 1962), constituyéndose en uno de los factores básicos del proyecto de emancipación americana:

San Martín, Páez, Monteagudo, Santander, O’Higgins, Unáneu, Nariño, Soublette, Montillo, Rivas, Pueyrredón, Zapiola, Belgrado, Hidalgo, Morelos, Urdaneta, y tantos otros, dieron carácter singular a sus propios compromisos que sítenían raíces comunes (Cavieres, 2012:30).

\section{Primeros intentos de proliferación de la masonería en Chile}

A comienzos del siglo XIX la sociedad hispanoamericana se enfrentaba a cambios socioculturales y políticos significativos que condicionaron el tránsito de una sociedad tradicional a una que intentará insertarse en la modernidad. François Chevalier (1999) ha señalado que los procesos históricos ocurridos en Hispanoamérica producen cambios culturales y de comportamientos por la llegada de ideas liberales. Además destaca la importancia de las formas de sociabilidad como clubes, tertulias literarias y las logias masónicas. Estas sociabilidades poseen un carácter igualitario y voluntario, y son una manifestación de la modernidad. A comienzos del siglo XIX 
se fundó en la ciudad de Concepción un club revolucionario, integrado por «José Antonio Prieto, Manuel Bulnes, los capitanes Venancio Escamilla, Francisco Calderón, José Cruz, Bernardo O’Higgins y el español Carlos Spano» (Del Solar, 2010), el cual tuvo por finalidad dialogar las ideas ilustradas.

La presencia de la masonería como institución organizada es de complicado análisis a comienzos del siglo XIX, pero se infiere a través de personas en calidad de masones que participaron por la causa de la independencia, como José de San Martín, José Miguel Carrera, Simón Bolívar y Manuel Blanco Encalada. Sin embargo, encontramos una forma de sociabilidad denominada logia Lautaro (Pinto, 1966:74), que existió en Chile entre 1817-1820, integrada principalmente por militares chilenos y argentinos ${ }^{4}$ (Sepúlveda, 1994: 43), con un objetivo político concreto: la independencia de Chile y la liberación del Perú. El juramento de los miembros de esta sociedad pro-independencia es testimonio de su convicción por la emancipación:

Nunca reconoceremos un gobierno un gobierno legítimo de nuestra patria sino aquel que sea elegido por la libre y espontánea libertad del pueblo, siendo el sistema republicano el más adaptable al gobierno de las Américas. Propenderemos por cuantos medios estén a nuestros alcance a que los decidan por él (Galleguillos, 2012: 4-5).

La logia Lautaro chilena «fue parte de un proceso regional de proliferación de logias cívico-militares; durante su existencia surgieron paralelamente al menos dos logias más: Caballeros Orientales, en Montevideo, y la logia Central de la paz de América del Sur, en el Alto Perú». Sin embargo, esta última se trataría «de la primera logia masónica establecida en la región» (Del Solar, 2012: 25).

Pero, los problemas relacionados con la proliferación y convivencia de las nacientes logias llevaron a divisiones internas debido a los distintos proyectos de nación, lo que llevó a las disoluciones de estas y a enfrentamiento entre sus miembros. No obstante, es importante aclarar que en términos formales las sociedades secretas durante las «Guerras de Independencia no estuvieron afiliadas a ninguna Obediencia masónica [...] se trataría de una construcción original, una apropiación criolla del modelo asociativo secreto» (Del Solar, 2012:27). A pesar de los intercambios culturales: ${ }^{5}$

4. Formaron el cuadro logial, según Antonio R. Zúñiga, San Martín, O’Higgins, Antonio y José Irisarri, Francisco Calderón, Manuel Borgoño, Juan Cabot, Bernardo Monteagudo, Mariano Larrazábal, José Bernardo Cáceres, Mariano Necochea, Ambrosio Cramer, Manuel Blanco Encalada, Matías Zañartu, Tomás Guido, Hipólito Villegas, José Ignacio Zenteno, Ramón Freire, entre otros.

5. Los miembros de la Orden estuvieron alineados con los principios ilustrados, ya que defendieron los principios de libertad, igualdad, progreso, soberanía popular y criticando duramente a la sociedad y cultura de la época, así como el excesivo poder de los reyes. Promovían la separación de poderes del Estado y la 
La masonería en Chile no logró establecerse, ya sea por la creación de facciones al interior de los ejércitos y la división de las logias; por los conflictos [...] luego de la independencia o por [los] conservadores que frenó los avances del liberalismo en los procesos fundacionales de las naciones en América del sur (Del Solar, 2010: 7).

Por ello, después de la abdicación de O’Higgins, entre 1823 y 1831, se sucedieron varios gobiernos breves que trataron de lograr la organización del Estado. Fue una etapa de gran inestabilidad política respecto al tipo de gobierno, los gobernantes tuvieron la voluntad de dar a la nación la forma más adecuada de organización (Eyzaguirre, 1961). Ejemplo de ello, encontramos dentro del orden jurídico varios ensayos constitucionales entre 1823 y 1828, los cuales estuvieron centrados en moralizar a la sociedad, establecer un estado federal, equilibrar el peso de los poderes ejecutivo y legislativo, y otorgar grandes libertades a las personas.

La presencia de la masonería en Chile tendrá relación con la Gran Colombia, donde se creó un poder regulador que fundó sobre la base de un Gran Oriente y con tuición directiva sobre los 33 grados del rito escoces antiguo y aceptado. Los antecedentes permiten decir, casi con seguridad, que su nombre distintivo fue el de Gran Oriente N. Colombiano, y ya estaba estructurado en 1824. Antonio Velero recibió en el Perú la misión de regularizar los cuerpos masónicos existentes y los dispersos, formando el Capítulo Rosa Cruz, Grado 18.

Este Capítulo delegó en Manuel Blanco Encalada, la autoridad suficiente para fundar logias en Chile (Respetable Logia $\mathrm{N}^{\circ} 75$, 1950: 252). Tal vez por asuntos de carácter político, solamente se pudo fundar en Santiago el 15 de marzo de 1827 la logia Simbólica Filantropía chilena6 (Sepúlveda, 1994: 48), que quedó bajo la directa dependencia del Capítulo Rosa Cruz Regeneración del Oriente de Lima, y por su intermedio del Gran Oriente N. Colombiano. Representa «una síntesis de las guerra de independencia»y los integrantes «fueron veteranos de las guerras napoleónicas», siendo estas una instancia de «socialización más importante de la masonería entre los ejércitos Hispanoamericanos» (Del Solar, 2010: 8; Pinto, 1966: 83-105). Esta logia fue otro ejemplo de asociación militar patriota y a través de esta,

promulgación de un régimen representativo, para lo cual era necesario establecer un contrato social que delimitara los deberes y atribuciones de los gobernantes y derechos de los gobernados.

6. Presidida por Manuel Blanco Encalada; Manuel Gandarillas como primer Vigilante; Manuel Rengifo Cárdenas como Segundo Vigilante; Tomás Ovejero como Orador; Juan Francisco Zegers como Secretario; Ventura Blanco Encalada como Tesorero; y Miguel Arguelles como Experto. Conformaron el taller Vicente Tur, Francisco Doudther, Victoriano Garrido, José Manuel Gómez de Silva, Jorge Lyon, Carlos Renard, José Domingo de Otaegui y Mariano Álvarez. Es importante señalar que ninguno de los miembros figura en los cuadros de las logias lautarinas. 
Blanco «pensó aunar opiniones auténticamente republicanas que pudieran influir con serenidad, en el establecimiento de un sistema de gobierno que permitiera, dentro de las ideas liberales, afianzar la evolución democrática» (Pinto, 1966: 121). Pero no transcendió debido a los problemas de sus miembros y de las instituciones de la incipiente nación.

Pese a las dificultades políticas en Chile, hubo importantes avances: se abolió definitivamente la esclavitud, se expulsaron los peninsulares de todo el territorio nacional, y se disolvieron las andanzas de asaltantes y cuatreros que asolaban los campos de Chile. La mayoría de los gobiernos de este período fueron liberales, y los conservadores conformaron una fuerte oposición. En 1829, liberales y conservadores se enfrentaron en una guerra civil. En la Batalla de Lircay (17 de abril de 1830) los liberales fueron derrotados y los conservadores asumieron el poder.

Con el triunfo de los conservadores en Lircay inicia la república conservadora. Destaca el ideario portaliano, según el cual el poder debía estar en la figura de un Presidente de la República con numerosas atribuciones. Portales estaba convencido de que las condiciones sociales y culturales del país no permitían el funcionamiento de un régimen democrático, por lo que antes de practicar esa forma de gobierno era necesario establecer un régimen autoritario y fuerte que cumpliera con el anhelo de educar a la población y cambiar su mentalidad. Las principales medidas fueron: censura a la prensa opositora, persecución y destierro a los opositores del gobierno, establecimiento de consejo de guerra para los delitos políticos, entre otros. Las ideas de Portales fueron recogidas por Mariano Egaña al elaborar la Constitución de 1833, base del sistema portaliano y de la república conservadora.

En el primer quinquenio de Prieto se afianzó el sistema imperante, conservador en lo político como y católico en lo religioso, por la eficiencia de funcionarios en las tareas del Estado; pero dentro del gobierno hubo presencia de miembros de la institución, como el masón Manuel Rengifo Cárdenas, designado como Ministro de Hacienda.

La conformación del orden autoritario no significó que los principios del ideario liberal se debilitaran; por el contrario, entre las décadas de 1830-1850, el liberalismo cristalizó en una nueva forma de sociabilidad. Una de ellas liderada por Manuel José Gandarillas, con la fundación del diario El Philopolita, que posteriormente daría el nombre al grupo. Sus integrantes fueron la familia Errázuriz, los pipiolos recalcitrantes y los militares dados de baja después de Lircay. El grupo se centró en discutir las políticas de Portales e impedir la reelección del general Prieto en 1834 (García Valenzuela, 1949: como se citó en Gazmuri, 1992: 173).

En 1842 se formó la organización denominada Sociedad Literaria, presidida por José Victorino Lastarria, considerado como un verdadero programa de la juven- 
tud de la época, con proyecciones políticas. La institución fue creada, como «un movimiento de renovación de ideas y de las letras y como el hogar intelectual de hombres de gran figuración en la historia de Chile» (Sepúlveda, 1994: 60). En 1849 se funda el Club de la Reforma, cuyo objetivo era «cohesionar la oposición liberal al Gobierno»; proclamó el reconocimiento de la razón, la soberanía como base de toda política, la fraternidad universal como vida moral. Su consigna fue la trilogía, Libertad, Igualdad y Fraternidad (Sepúlveda, 1994: 70).

Otra forma de sociabilidad fue la Sociedad de la Igualdad, fundada en 1850 por Francisco Bilbao y Santiago Arcos, destinada a difundir las ideas de libertad e igualdad y realizar debates sobre temas sociales.

La finalidad fundamental de la Sociedad de la Igualdad) fue la reforma social y como medio de trabajo para alcanzarla adoptó algunos principios que, junto con que debían hacer carne entre los adeptos constituían una especie de juramento en la incorporación de ella: La soberanía del pueblo como base de la política; la fraternidad universal como vida moral. Por otra parte se exigía a los artesanos y obreros la promesa solemne de moralidad en las costumbres y en la conducta privada (Barahora, s/f).

Esta agrupación manifestó una fuerte oposición al pensamiento conservador y a la Iglesia Católica, y fue disuelta violentamente por el gobierno; sus dirigentes fueron exiliados. Pese al reiterado uso de la fuerza contra los grupos liberales, los conservadores no pudieron evitar la consolidación de este sector político que, a partir de 1861, gobernaría el país modificando las leyes y la orientación del gobierno.

Marcial Sánchez Gaete (2011) ha señalado que las logias masónicas en Chile promovieron «el laicismo anticlerical representado por Francisco Bilbao quien tradujo obras de Lamennais; por José Victorino Lastarria que en 1839 introdujo el positivismo en el Instituto Nacional» (150-151). En 1872 masones de logias de diversos orígenes nacionales, incluyendo a David Trumbull:

[...] fundaron en Valparaíso el Colegio Blas Cuevas, objetado en nombre de la Constitución por el Gobernador Eclesiástico Mariano Casanova por no incluir enseñanza religiosa. En 1873 el puertorriqueño José María de Hostos [...] propuso que una buena educación científica hacia la mujer, podía remplazar en su pensamiento a Dios y a la Iglesia católica (Sánchez, 2011).

Miguel Guzmán-Stein, expresa que el debate entre la religiosidad católica y la cultura liberal incidirá directamente en el replanteamiento del modelo y procesos de formación del Estado, y en la metodología y filosofía católica, y que se expresan 
en las aparentes antítesis de fe-razón, libertad-autoridad y tradición-progreso, a los que habría que agregar el de dogma-fe versus ciencia-razón:

[...] el liberalismo propone la secularización de la enseñanza como única vía para formar a las nuevas generaciones en la teoría y la práctica de la libertad plena, sin ataduras, en donde la razón y la ciencia jueguen un papel fundamental en educación; ésta forma parte del proceso de secularización del Estado (Guzmán: 2009).

\section{Masonería y su institucionalización}

La masonería chilena se fundó en la coyuntura de 1848, y no fue, al menos inicialmente, una copia sino más bien una filial de la matriz europea. Tal como aquella «se trató de una sociedad secreta, de iniciados, y que si bien no dejaba de tener objetivos políticos no declarados, su accionar proseguía horizontes más amplios; la cultura, las costumbres y el conocimientos en materias de su interés» (Galleguillos, 2012: 6).

Es significativo comprender que el espacio masónico sudamericano se constituyó a través de dos vías: una nacional y otra cosmopolita. La primera «vinculada al proceso de institucionalización de Obediencias soberanas», y la segunda «gracias a los grandes flujos migratorios, a la circulación regional y a los exilios políticos» (Del Solar, 2012: 41), que implicará no solo la fundación de logias, sino también el establecimiento de redes internacionales donde circularán masones de distintas nacionalidades y obediencias (Hazard, 1991: 237). En este sentido, la fundación de logias será un proceso sostenido en el que se distinguen tres períodos: «1853, cuando se constituyó el triángulo de logias que servirá de base para la fundación de nuevos talleres; en 1860, que es cuando se consolidó la comunidad local y [...] 1862 donde se identificó la actividad debido al cisma con el Gran Oriente de Francia» (Del Solar, 2012: 61).

Esta sociabilidad cosmopolita «la formaban en su mayoría comerciantes y artesanos extranjeros de origen europeo y norteamericanos, siendo un factor determinante en su proliferación en las ciudades porteñas, centros del comercio nacional e internacional del Pacífico» (Del Solar, 2012: 62). Caracterizadas por una hermandad con principios laicos, con una visión de ayuda mutua; con una visión política, social y económica distinta; las logias fueron un centro de diálogo y de refugio fraternal para extranjeros (Del Solar, 2010: 9), ya que muchos no profesaban el catolicismo.

La ciudad de Valparaíso será una ciudad cosmopolita, es decir, llegarán extranjeros protestantes y comerciantes. La ciudad de Talcahuano facilitará el crecimiento y avance de la masonería, pues el auge económico de la zona sur del país propiciará 


\begin{tabular}{|c|c|c|}
\hline TABLA 1 & Logias formadas en Chile $1850-1862$ & \\
\hline Año & Nombre de la logia & Ciudad \\
\hline 1850 & L'Etoile du Pacifique & Valparaíso \\
\hline 1853 & Pacific Lodge & Valparaíso \\
\hline 1853 & Bethesda & Valparaíso \\
\hline 1853 & Unión Fraternal & Valparaíso \\
\hline 1854 & Capítulo Grado $18^{\circ}$ Rosa Cruz & Valparaíso \\
\hline 1856 & Estrella del Sur & Concepción \\
\hline 1857 & Hiram & Copiapó \\
\hline 1858 & Southerm Cross & Valparaíso \\
\hline 1860 & Aurora de Chile & Concepción \\
\hline 1860 & Aurora. & La Serena \\
\hline 1860 & Consejo Grado $30^{\circ}$ Caballero Kadosh & Valparaíso \\
\hline 1862 & Orden y libertad & Copiapó \\
\hline 1862 & Progreso & Valparaíso \\
\hline 1862 & Fraternidad & Concepción \\
\hline
\end{tabular}

Fuente: Del Solar, 2012: 62.

la llegada de extranjeros en busca de fortuna y mejores oportunidades para invertir y apoyar en el desarrollo y progreso económico y cultural. En cambio, Santiago tardó más en la instalación debido a la tradición conservadora y presencia católica de la elite imperante. En la siguiente tabla se pueden observar las logias fundadas en Chile entre 1850 y 1862.

Desterrado de Francia a raíz de la revolución de 1848, el abogado francés Monsieur Gent abandonó su país y estableció su residencia en el puerto de Valparaíso. Encontró allí a varios masones que había conocido en Francia, y estos lo pusieron en contacto con otros miembros de la Orden que también residían en la ciudad, todos estaban inquietos y animados a fundar una logia. Oviedo señala que el recuerdo de aquella heroica jornada en pro de la libertad despertaba entusiasmo entre los concurrentes; Monsieur Gent propuso a sus compañeros fundar una Logia Masónica 
en Valparaíso: la proposición fue aceptada y pocos días después, el 7 de agosto de 1850, se declaró la logia L'Étolile du Pacifique bajo la obediencia del Gran Oriente de Francia (Oviedo, 1929: 102; Pinto, 1966: 173). Esta fundación de la Logia en Valparaíso es cuestionada por Böhm, «quien considera al sastre J. B. Dubreuil como el verdadero fundador» (Böhm, 1979: 58), quedando por este último Jean Baptite Dubreuil7 (Sepúlveda, 1994: 72).

Los trabajos no pudieron empezar de forma inmediata, porque carecían de la autorización del Oriente de Francia; la lentitud de los medios de comunicación no daba esperanzas de lograr la autorización a corto plazo. Aprovechando el viaje de uno de los miembros del taller, se elevó al Gran Oriente de Francia la solicitud de autorización para constituirse en Valparaíso y trabajar en instancia. Después de un año de espera llegó la autorización, mediante el decreto de 12 de noviembre de 1851, dictado por Lucien Murat, Gran Maestro del Gran Oriente de Francia, que autorizaba a la logia para instalarse y empezar sus trabajos bajo el Rito Escocés Antiguo y Aceptado y en el grado de aprendiz. Según una carta citada por Böhm y por Gazmuri, los franceses que organizaron la logia L'Étolile du Pacifique eran, al parecer, artesanos (Böhm, 1979; Gazmuri, 1992: 174; Respetable Logia $\mathrm{N}^{\circ} 56,1952: 252$ ).

Es importante destacar lo señalado por Hugo Galleguillos (2012), que la relación fundacional entre logia L'Étolile du Pacifique y el Gran Oriente francés deja en evidencia que algunos de sus miembros ya habían sido masones en Francia antes de llegar a las costas del Pacífico.

La logia era visitada por miembros de distintas profesiones y oficios, por ejemplo, «jardineros, carniceros, panaderos, carpinteros [...], relojeros, joyeros, sastres y sombrereros», y por su carácter comercial la logia agrupaba: «negociantes, mercaderes, capitanes de navíos, comisionistas, capitalistas, abogados» (Del Solar, 2012: 72), permitiendo establecer redes comerciales «profanas» dentro de la logia.

La presencia de hombres de diversos credos, oficios y lugares, no fue un impedimento sino que ayudó a establecer redes de sociabilidad entre sus miembros a través del intercambio comercial, lo cual permitió la circulación de ideas políticas, filosóficas y religiosas. Dicho clima presidió: «la creación de la logia francesa, que inició sus actividades en medio de este activo comercio y del ir y venir de los barcos cargados de productos que recalaban en sus muelles» (Sepúlveda, 1994: 73), lo que implicaba la posibilidad de acoger fraternalmente a distintos miembros en la logia.

El ejemplo de los masones franceses establecidos en Chile, fue seguido por ingleses y norteamericanos, quienes resolvieron fundar un taller de habla inglesa Pacific Lodge $\mathrm{N}^{\circ} 1$, solicitando sin éxito Carta Patente a la Logia de California. No 
obstante, en 1853 fue regularizada por la Gran Logia de Massachussets, obteniendo carta constitutiva, para ser solemnemente instalada en Valparaíso el 14 de diciembre de 1854 bajo el nombre de Bethesda (Coyoumdjian, 1995:186-187); presidió el taller Edwards W Sarton. ${ }^{8}$ Es importante destacar la designación de David Trumbull, misionero presbiteriano norteamericano, que luchó contra la omnipotencia de la iglesia católica oficial y trabajó por establecer la primera iglesia protestante. Estas logias trabajaban en francés e inglés, lo cual dificultaba el ingreso de chilenos.

Los primeros masones chilenos comienzan a organizarse bajo la conducción de quien sería el verdadero fundador de la masonería chilena, Manuel de Lima (Galleguillos, 2012: 7). Comprendió la situación de la masonería en Chile, «desconocida en su verdadera esencia y significado, y los pocos que de ella tenían algunas noticias, estaban imbuidos por errores y nociones inexactas acerca de sus finalidades». Además señalaba que debía ser cultivada y propagada por chilenos que supieran «aprovechar sus enseñanzas y sembrarlas en la sociedad. Comenzó a exponer en forma clara los principios y finalidades de la institución» (Respetable Logia $\mathrm{N}^{\circ} 75,1950$ : 253).

Se cree que recibió ayuda o consejos de los miembros de la logia L'Étolile du Pacifique, que ya contaba con algunos miembros chilenos y argentinos que ahora pasaban a integrar la nueva logia en formación llamada Unión fraternal, nacida bajo los auspicios del Gran Oriente de Francia, un 27 de julo de 1853. La logia se multiplicó y hacia 1855 tenía 42 miembros, entre los cuales estaban «Federico Schwager, José Victorino Lastarria, Domingo Faustino Sarmiento y los ilustres miembros que siguieron a Manuel de Lima en la conducción del taller, como Juan de Diso Arlegui, Enrique Pastor López y Francisco Javier Villanueva ${ }^{9}$ (Galleguillos, 2012: 7).

La importancia de esta logia implicaba la pervivencia de la masonería en el país, debido a la gran movilidad de las otras logias, pues sus miembros eran principalmente comerciantes, lo cual podría poner en peligro la continuidad de la Orden. En 1854 se formó el Capítulo Rosa Cruz, como un intento de «establecer instancias paralelas a la logia madre que ayudaría asegurar la pervivencia de la masonería en Valparaíso» (Del Solar, 2012: 82), respondieron con el deseo de dar el grado $18^{\circ}$ a los miembros Jean Dubreuil, de L'Etoile du Pacifique; Manuel de Lima, de Unión Fraternal; y Charles Ward, de Bethesda; entregada a todos los venerables maestros de las logias del puerto con el objeto de fortalecer e intercambiar principios propios de la Orden, pero esta iniciativa perdió fuerza contra la acusación del presidente del Capítulo, que terminó en la expulsión y salida de varios de sus miembros (Del Solar, 2012: 83).

8. Fueron elegidos Vigilantes M.I. Hobson y J.R. Lyon. Integraron además el cuatro otros nueve masones.

9. La Gran Logia de Francia prestó su aprobación el 4 de abril de 1854, aceptando igualmente las proposiciones de Manuel de Lima en cuanto al uso del idioma castellano y de elegir directamente a sus autoridades. 
La fundación de la logia Unión Fraternal ${ }^{10}$ facilitó la iniciación de masones criollos y el ingreso también a argentinos, ingleses, franceses, españoles y alemanes, lo que evidencia el carácter cosmopolita de las logias masónicas. En 1856 fue elegido como venerable maestro Juan de Dios Arlegui, siendo el primer chileno en alcanzar tal designación.

Es importante considerar que las logias L'Étolile du Pacifique y Unión fraternal percibían un sentimiento de abandono por el Gran Oriente de Francia. El venerable maestro Arlegui inició intercambios epistolares con el Gran Oriente, dando cuenta del silencio e indiferencia del poder central. Fernando Rodella se encontraba en Francia y actuó de representante de la logia ante el Gran Oriente, destacando que los problemas de comunicación impedían el ingreso de nuevos iniciados en Valparaíso. El trabajo logial para 1858 era complicado, pues el venerable maestro Arlegui centraba su preocupación en la escasa respuesta a los trabajos de docencia, el reclutamiento de miembros, los aumentos de salarios y exaltaciones, y la consolidación de la institución, no solo en el puerto sino también en el país.

$\mathrm{Si}$ consideramos que las logias surgieron gracias a «la gran movilidad de los comerciantes entre los puertos de Valparaíso y Talcahuano» (Del Solar, 2010: 10), es posible comprender la llegada de la masonería a los valles de Concepción y Copiapó. El primero gracias a Enrique Pastor López, quien traslada su residencia a la ciudad de Concepción en 1856, iniciando un nuevo núcleo masónico con la fundación de la logia Estrella del Sur, solicitando Carta Constitutiva al Supremo Consejo de Perú. En un principio funcionaba solo por «extranjeros», más tarde fueron iniciados chilenos.

Durante cuatro años el taller desarrolló actividades bajo los auspicios del Supremo Consejo; tras una serie de disidencias que sufrieron en su seno y que afectaron al diputado que la logia tenía en Lima, ${ }^{11}$ hacia fines de 1860 se integra al Gran Oriente

10. Oficialidad temporal Unión Fraternal: VM:. Manuel de Lima, Primer Vigilante Philippe Calmann, Segundo Vigilante Guillaume Holthusen, Orador Federico Álvarez de Toledo, Secretario Antonie Auguste Bonnet, Tesorero, Frederic Guillaume Eichhoff, Guarda Sello, Bernard Barstow Neummann, Experto Samuel Keeling.

11. Los problemas surgidos en Perú fueron producto de un cisma ocurrido al separarse un numeroso grupo de hermanos dependientes del Gran Oriente Peruano, en 1857, para constituir una Gran Logia simbólica, que fue instalada el 9 agosto de 1858. Estos hermanos eran los integrantes de las Logias Concordia Universal, Estrella Polar y Unión y Virtud. Muchos otros hermanos, alejados también del Gran Oriente Peruano, prepararon una Asamblea Masónica a la que adhirieron los tres Talleres fundadores de la Gran Logia independiente, que se celebró el 7 de noviembre de 1859. (López, 1958). Este nuevo Gran Oriente del Perú fue solemnemente instalado el 30 de enero de 1860. Estos acontecimientos fueron comunicados a todos los Talleres de la Obediencia, incluyendo a la R. Logia «Estrella del Sur», de Concepción. El Gran Oriente del Perú (el primitivo) emitió una circular, el 1o de febrero de 1860, declarando «espurio, atentatorio e irregular ante el mundo masónico, el titulado G.O.N. que ha erigido la facción disidente e irregular de la masonería del Perú». Enrique Pastor López, en 1903, recordaba que «a consecuencia de 


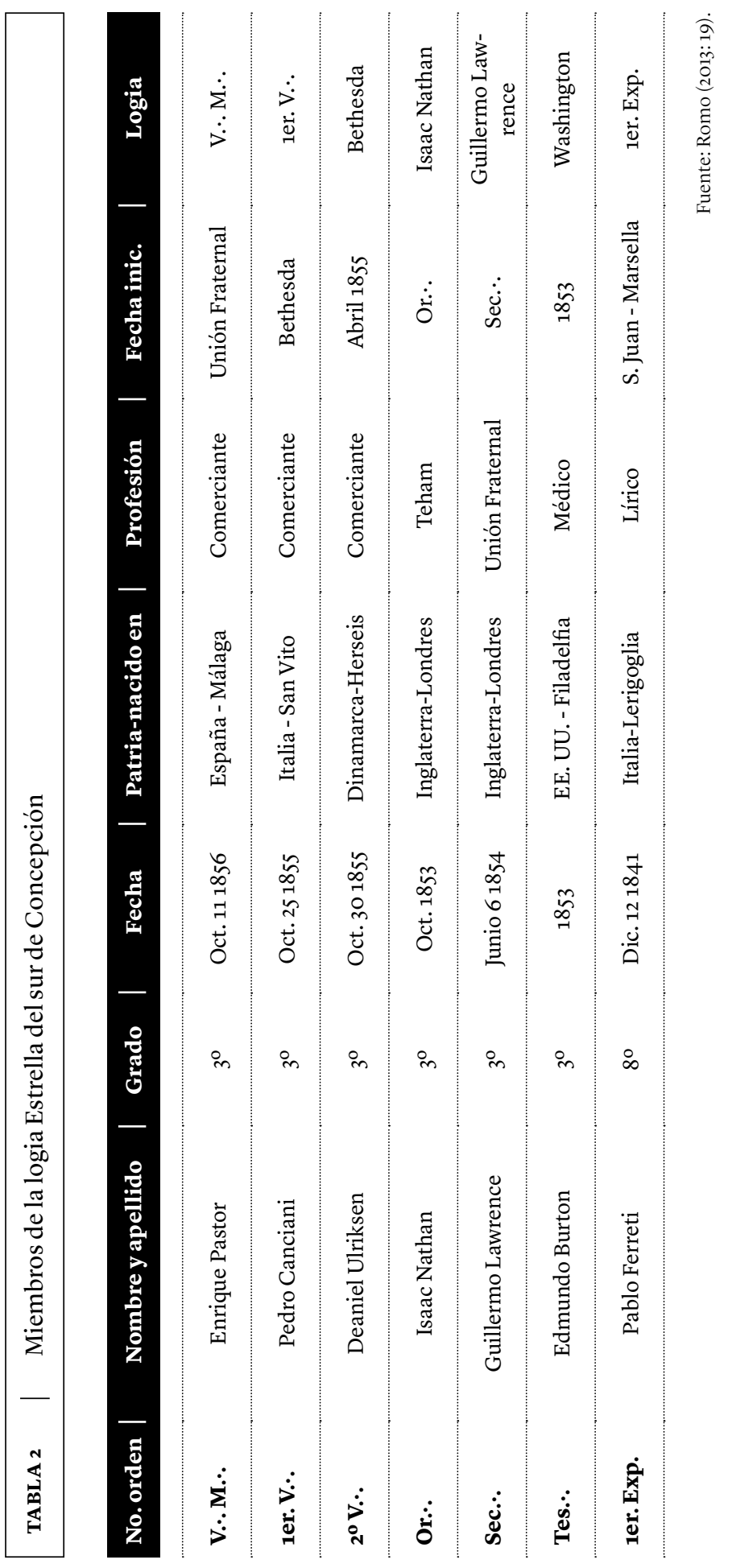


de Francia cambiando su nombre por el de Aurora de Chile (Gazmuri, 1992: 194). «Un intento de homogeneización de la estructura de la masonería chilena», imitando el modelo cultural más admirado por los chilenos: Francia. Posteriormente, el 14 de mayo de 1862 esta logia «da origen a la respetable logia Fraternidad» cuyo fundador y primer venerable maestro fue Enrique Pastor López (Galleguillos, 2012: 7; Respetable Logia $\left.\mathrm{N}^{\circ} 75,1950: 253\right)$.

El segundo punto fue la ciudad de Copiapó, donde fueron fundadas las logias Fraternidad, Hiram, y Orden y Libertad. La logia Fraternidad habría funcionado hacia 1860 por dispensa de la Gran Logia de Massachusetts, otorgándosele la Carta-Patente el 15 de diciembre de 1859, su presencia fue estímulo para la formación de la logia de habla castellana que vendría después. Sus integrantes fueron ingleses y norteamericanos vinculados a las actividades mineras y manteniendo vínculos con los masones nacionales (Sepúlveda, 1994: 81). La logia permaneció en Copiapó hasta 1869 , año en que se extendió su autorización para trasladarse al vecino puerto de Caldera.

En 1861 los masones chilenos realizan las primeras gestiones para levantar columnas. La fundación de la tercera logia propiamente chilena fue el 11 de enero de 1862, con el nombre de Orden y Libertad, bajo la adopción del Rito Escocés, Antiguo y Aceptado, solicitaron Carta Constitutiva al Gran Oriente de Francia. La primera actividad de la logia fue «[...] crecer mediante iniciaciones y afiliaciones, colocando entre columnas a [...] abogados, profesores, ensayadores de minerales» (Sepúlveda, 1994: 84). Contemporánea y un poco anterior a esta logia fue la logia Hiram, que trabajada en la ciudad: sobre su origen no se ha encontrado noticias, antecedentes señalan que no dependía del Gran Oriente de Francia.

La logia Orden y Libertad no alcanzó a obtener la Carta Constitutiva del Gran Oriente de Francia, bajo cuyos auspicios se había fundado, pues por aquella época sobrevino la crisis que puso fin a la jurisdicción de dicha potencia sobre las logias chilenas (Respetable Logia $\mathrm{N}^{\circ} 75,1950$ : 253). Su venerable maestro fue Guillermo Eduardo Gotschalk, médico danés, protestante, y cónsul de su país en Copiapó. Ese mismo año se funda en Valparaíso la logia Progreso, bajo los auspicios de la logia Unión Fraternal y que sería la cuarta logia chilena que colaborará en la futura Gran Logia de Chile, fue su venerable maestro Blas Cuevas Zamora.

ciertas irregularidades que tuvieron lugar en el Gran Oriente del Perú, creímos de nuestro deber regularizar nuestros trabajos separándonos de aquel cisma y nos dirigimos al Gran Oriente de Francia en demanda de una carta constitutiva que autorizara nuestros trabajos, la que nos fue concedida con fecha 12 de septiembre de 1860 con el título distintivo de Aurora de Chile (...)». Como se comprende, esto es una confusión de Pastor López, pues lo que ocurrió el 12 de septiembre fue la reunión en instancia del nuevo Taller. El discurso de Pastor López en 1903, aparece citado en Romo (2013: 19). 
El avance de la masonería en Chile estaba organizado entre Valparaíso, Concepción y Copiapó. Hacia 1860 los factores que dificultaban la institucionalización de la Orden en Chile eran la distancia con la autoridad central, es decir, con la Gran Logia de Francia, la solicitud del envío de material para la docencia del Rito, las autorizaciones para las iniciaciones, exaltaciones siendo necesarios para la Orden y temor por que las logias en Chile podrían abatir columnas.

La alternativa era buscar una estrategia para independizarse del Gran Oriente de Francia y constituir una potencia masónica autónoma, sin caer en la irregularidad y sin faltar a los juramentos de adhesión. Es importante considerar este problema sin solución posible. No obstante, se produjo un acontecimiento que permitió a las logias de Chile obtener la independencia a que tanto aspiraban.

La situación política de Francia, a raíz del golpe de Estado del 2 de diciembre de 1852 por Napoleón III, quien estuvo en la disyuntiva entre suprimir o vigilar a la Orden, «creyendo que su influencia pudiese manifestarse hostilmente al nuevo gobierno» (Wirth, 1995: 85), pero los consejeros consideraban mejor la simpatía ante que la hostilidad. El detonante fue la resolución que el Emperador Napoleón III adoptó con respecto al Gran Oriente. El escándalo deriva al parecer por la resistencia de Murat de abandonar su cargo, pues «no poseía las condiciones de carácter, la inteligencia y moralidad para ejercer adecuadamente el cargo, pues cometió una serie de desaciertos administrativos y sometiendo a la institución a un gobierno absoluto, semejante al que estaba el pueblo francés» (Wirth, 1995: 85), lo que condujo al emperador Napoleón III a imponer el nombre del profano Pierre Magnan, al nombrarlo por Decreto Imperial N 9.862 del 11 de enero de 1862, Gran Maestro del Gran Oriente francés.

Esta caída de la potencia en la irregularidad causó profundo revuelo en el propio Gran Oriente y también en Chile. Entre marzo y abril de 1862 los venerables maestros y los Oficiales de las logias: Unión Fraternal Manuel de Lima, Fraternidad Enrique Pastory Orden y Libertad Guillermo Gotschal, se reunieron para analizar la situación y resolver la materia, adoptándose los siguientes acuerdos:

1. Informar de los acontecimientos ocurridos en el seno del Gran Oriente a las Resp. Logias Aurora de Chile de Concepción y Orden y Libertad de Copiapó, insinuándoles la idea de formar una organización masónica nacional, soberana e independiente, luego de desafiarse del Gran Oriente; 2. Organizar una cuarta logia simbólica que, con las tres existentes, permita la formación regular de una Gran Logia como gobierno de la Masonería chilena; y 3. Fundar un Poder Masónico Nacional sobre la base antedicha, bajo el título distintivo de Gran Logia de Chile y de acuerdo a las tradicionales normas que regulan estos organismos (Sepúlveda, 1994: 92). 
La consecuencia fue desconocer y negar la autoridad del Gran Oriente, declarándose independientes. De la logia Unión Fraternal salieron los fundadores de la logia Progreso de Valparaíso. La importancia de la nueva logia no residió solamente en ser el segundo taller fundado en la ciudad, sino ser una cuarta columna de apoyo para la fundación de la Gran Logia de Chile, prestando equilibrio y armonía en la tarea de su construcción.

Asimismo se acordó designar representantes de la Logia ante los organismos que se estaban creando en el puerto al VH:. Pantaleón Uriarte, Primer Vigilante de la Unión Fraternal (Sepúlveda, 1994: 94). Para fundar en Valparaíso la Gran Logia de Chile, el 29 de abril de 1862, declararon la formación de la Gran Logia, quedando instalada en Valparaíso el 24 de mayo del mismo año con la concurrencia de 30 masones y tres delegados por cada una de las Logias que conformaran el nuevo organismo soberano: «Unión Fraternal y Progreso de Valparaíso, Fraternidad, de Concepción y Orden y Progreso, de Copiapó (Sepúlveda, 1994: 95), eligieron autoridades y adoptaron resoluciones ampliamente valederas para el futuro gobierno simbólico. Proclamada solemnemente esta resolución, se procedió a la elección de autoridades, como sigue:

Ser:. Gra:.Maestro Juan de D. Arlegui

Gr:. Dip:. Gr:. Maestro Melitón Caso

Primer Gr.. Celador Francisco J. Villanueva

Segundo Gr.. Celador Manuel de Lima

Gran Sec. Gral Manuel A. Medina (Sepúlveda, 1994: 103)

El Gran Maestro Juan de Dios Arlegui, dispuso de una circular explicando los antecedentes y las causas que habían determinado el establecimiento de la Gran Logia de Chile. Sin embargo, la Logia L'Étolile du Pacifique envió un informe acerca de la situación producida por las logias en Chile y los procedimientos que llevaron a la formación de la Gran Logia de Chile. Los miembros de la logia francesa se encargaron de desprestigiar internacionalmente a la Gran Logia de Chile, aduciendo irregularidades en su constitución. La contestación del Gran Oriente de Francia fue:

Acuerda declarar la Unión Fraternal destruida y borrada del calendario del Gran Oriente de Francia por haber faltado a su juramento e invitar a todas las logias de la correspondencia a cortar toda relación con ese pretendido Poder [la Gran Logia de Chile] y publicar la presente decisión en el Boletín del Gran Oriente (Sepúlveda, 1994: 105). 
La logia Unión Fraternal $\mathrm{N}^{\circ} 1$ comunicó al Gran Oriente de Francia su resolución de 9 de abril de desafiliarse y conformar el cuatro de la nueva Gran Logia, debido a la designación del «Mariscal Magnan en calidad de Gran Maestro de la Orden un atentado contra la Constitución y los Reglamentos Generales, que los miembros de este Taller han jurado obedecer y respetar» (Sepúlveda, 1994: 109).

Las primera potencia masónica que reconoció a la Gran Logia de Chile fue la Gran Logia de Massachusetts, el 30 de noviembre de 1862; después lo hizo la Gran Logia del Distrito de Columbia, el 13 de diciembre de 1863, y la Gran Logia Central de Francia el 21 de diciembre de 1864 (Wirth, 1995: 89). Los reglamentos generales fueron promulgados «por decretos de 18 de diciembre de 1862 y 30 de diciembre de 1865» (Wirth, 1995: 89), y durante la última década del siglo XIX fueron establecidas otras disposiciones que permitieron desarrollar los trabajos sin problemas.

\section{Conclusiones}

Las principales conclusiones del trabajo son:

1. El desarrollo de la masonería en el siglo XVIII de dio gracias a extranjeros ingleses y franceses, quienes a través del ejército ayudaron a transmitir su institucionalización en las colonas inglesas y españolas, lo cual permitió la propagación de ideas laicas a través del ejército y comerciantes militares y favoreció su expansión posteriormente en los colonos. Además, la fundación de logias permitirá el apoyo fraternal desde el extranjero, donde trabajaron masónicamente en los talleres y desarrollaron actividades comerciales que favorecerán la sociabilidad adentro y afuera.

2. La masonería es consecuencia de la llegada de la modernidad y el desarrollo de las formas de sociabilidad. Esto quedará evidenciado con la fundación de logias en territorio americano. En el caso chileno, la masonería inicia a fines del siglo XVIII y estará presente tanto con la fundación de logias y la participación de sus miembros en distintas actividades culturales y económicas. La institucionalidad en Chile se encuentra en 1848 con los movimientos liberales europeos que trajo como consecuencias la llegada de masones exiliados y también la apertura comercial, lo cual favorecerá la fundación de logias francesas y norteamericanas.

3. Las vías de ingreso fueron los puertos del Pacífico, Valparaíso y Talcahuano, con la llegada de militares, comerciantes, artesanos y profesionales; pero la consolidación fue a través del espacio local, con la iniciación de profanos chilenos que fundaron logias criollas. Valparaíso permitió la difusión de la masonería en 
Chile por la presencia de extranjeros británicos, franceses y norteamericanos, pero también significó un discurso político, ya que participaron líderes de la esfera pública local.

4. La participación de las logias Unión Fraternal y Progreso de Valparaíso, Fraternidad de Concepción y Orden y Progreso de Copiapó, permitieron establecer redes de sociabilidad e institucionalizar la Gran Logia de Chile en 1862, uno de los grandes logros de los masones chilenos. Entre los masones chilenos destaca Juan de Dios Arlegui, quien trabajó por institucionalizar la Orden a partir de la Unión Fraternal, y más tarde con la Gran Logia de Chile.

5. La presencia de la masonería durante los siglos XVIII y XIX fue una sociabilidad democrática de carácter moderna, ya que sus miembros aportaron ideas de desarrollo y progreso en los ámbitos cultural, ideológico, económico y político, que se evidenciará durante la segunda mitad del siglo XIX.

\section{Referencias}

AGULHON M. (2009). El círculo burgués. La sociabilidad en Francia, 1810-1848. Buenos Aires, Argentina: Siglo XXI Editores

AGULHON M. (1990). La sociabilidad como categoría histórica. En VV.AA. Formas de Sociabilidad en Chile. 1840-1940. Santiago, Chile: Fundación Mario Góngora.

BARAHORA, A. (s/f) Bosquejo histórico de la logia unión fraternal $N^{\circ} 1$, primera época 1853-1906. Santiago: Imprenta y Litografía Universo.

BASTIÁN, J.P. (1994). Protestantismos y modernidad latinoamericana: historia de unas minorías religiosas activas en América Latina. México: Fondo de cultura económica.

BÖHM, G. (1979). Manuel de Lima, Fundador de la masonería chilena. Santiago: Ediciones Universidad de Chile.

CAVIERES, E. (2012). Sobre la independencia en Chile. El fin del Antiguo Régimen y los orígenes de la representación moderna. Valparaíso: Ediciones Universidad de Valparaíso.

CHARTIER, R. (2003). Espacio público, crítica y desacralización en el siglo XVIII. Madrid: Editorial Gedisa.

CHEVALIER, F. (1999). América latina. De la independencia a nuestros días. España: Nueva Clío.

COYOUMDJIAN, R. (1995). Masonería de habla inglesa en Chile. Algunas noticias. Boletín de la Academia Chilena de la Historia, XLII (105), 105-208. 
DEL SOLAR, S. (2012). Las Logias de ultramar: En torno a los origenes de la Francmasonería en Chile 1850-1862. Santiago: Editorial Occidente.

DEL SOLAR, S.(2010). La Francmasonería en Chile: de sus orígenes hasta su institucionalización. Rehmlac, 2 (1), 2-15.

DEL SOLAR, S.(2004). «La Logia Lautaro: El poder de la masonería durante la dictadura de O' Higgins 1817-1822». Tesis para optar al grado de Licenciado en Historia, Pontificia Universidad Católica de Chile.

EYZAGUIRRE, J. (1961). La actitud religiosa de don Bernardo O'Higgins. Historia, (1), 7-46.

FERRER BENIMELI, J. (2009). Vías de penetración de la masonería en el Caribe. Rehmlac, 1 (1), 2-19.

FERRER BENIMELI, J. (1986). Masonería, Iglesia e Ilustración. Tomo III. Madrid: Fundación Española.

GONZÁLEZ BERNALDO DE QUIRÓS, P. (2008). La sociabilidad y la historia política. Nuevo Mundo Mundos Nuevos. Disponible en http://nuevomundo.revues.org/24082; Internet (consultada el 17 de febrero de 2008) doi: 10.400o/nuevomundo.24082.

GALLEGUILLOS MARDONES, H. (2012). Gran Logia de Chile desde su fundación en Valparaiso hasta su traslado a Santiago (1862-19o6). En Gran Logia de Chile, Historia, dilemas y futuro. Santiago: Ediciones Gran Logia.

GAZMURI, C. (1992). El 48 chileno. Igualitarios, reformistas radicales, masonesy bomberos. Santiago: Editorial Universitaria.

GUERRA, F.X.. (1993). Modernidad e independencia. Ensayos sobre las revoluciones hispánicas, México: Fondo de Cultura Económica.

GUZMÁN-STEIN, M. (2009). Masonería, Iglesia y Estado: Las relaciones entre el poder civil y el poder eclesiástico y las formas asociativas en Costa Rica (1865-1875). Rehmlac, 1 (1), 100-134.

HALPERIN, D. T. (1990). Historia contemporánea de América latina. Madrid: Alianza Editorial.

HAZARD. P. (1991). El pensamiento europeo en el siglo XVIII. Madrid: Alianza Editorial.

JOCELYN-HOLT, A. (2001). La independencia de Chile: tradición, modernización y mito. Santiago: Planeta.

LÓPEZ ALBUJAR, C. (1958). Masones y Masonería en el Perú. Lima: Imprenta José Pardo.

LYNCH, J. (1985). Las revoluciones hispanoamericanas, 1808-1826. Barcelona: Editorial Ariel.

MARTÍN, L. P. (2003). Las Logias masónicas. Una sociedad pluriformal. Hispania, LXIII/2, (214), 523-550. 
MEDINA, J. T. (1887). Historia del Tribunal del Santo Oficio de la Inquisición de Lima (1569-1820). Santiago: Imprenta Gutenberg.

OVIEDO, B. (1929). La masonería en Chile. Bosquejo histórico, la colonia la independencia, la República. Santiago: Imp. y Lit. Universo.

PARADA ULLOA, M. (2015). Ideas políticas liberales a través de la prensa en Chile entre 1812-1814. Revista Enfoques, XXVII (1), 103-125.

PEÑA CARVAJAL, O. (1962). Historia de la masonería chilena (1862-1962). Valparaíso: Gran Logia de Chile.

PICÓN SALAS, M, (1929). La masonería en Chile. Revista masónica, VI (64), 233-234

PINTO, F. (1966). La masonería su influencia en Chile. Santiago: Editorial Orbe.

RENAULT, A. (2009). La influencia de la masonería francesa en el Departamento Oriental de Cuba en los años veinte del siglo XIX. Los aportes de la posoprografía. Rehmlac, 1 (1), 75-89.

ROMO, M. (2013). Aportes de la Masonería peruana a la Masonería Chilena Archivo masónico, revista cuatrimestral, (31), 13-37.

ROMO, M. (2009). Ambrosio Sáez de Bustamante procesado por la Inquisición por el delito de Francmasonería. Archivo masónico, revista cuatrimestral, (17), 29-46.

RESPETABLE LOGIA N ${ }^{\circ}$ 56. (1952). El bicentenario de la iniciación del Ilustre Hermano Jorge Washington. Revista masónica, XXIX (9-10), 246-255.

RESPETABLE LOGIA, $\mathrm{N}^{\circ}$ 75. (1950). Bosquejo histórico de la francmasonería en Chile, desde 1827 a 190o. Revista masónica, XXVII (8), 251-257.

SÁNCHEZ GAETE, M. (2011). Historia de la Iglesia en Chile. Los nuevos caminos: la Iglesiay el Estado. Santiago: Editorial Universitaria.

SEPÚlVEDA CHAVARRÍA, M. (1994). Crónicas de la Masonería Chilena (1750-1944). Santiago: Ediciones Gran Logia de Chile.

VALDÉS-VALLE, R. (2009). Origen, miembros y primeras acciones de la masonería en El Salvador (1871-1872). Rehmlac, 1 (1), 156-171.

WIRTH, O. (1995). El libro del aprendiz. Santiago: Ediciones Gran Logia. 